\title{
Light and Electron Microscopic Observations of Cladosporium sp. Growing on Basidia of Exobasidium camelliae var. gracilis
}

\author{
C.W. Mims, ${ }^{*}$ and E.A. Richardson** \\ *University of Georgia, Department of Plant Pathology, Athens, GA 30602 \\ **University of Georgia, Department of Plant Biology, Athens, GA 30602
}

Cladosporium is a very large anamorphic fungal genus containing saprobic, endophytic, plant pathogenic and fungicolous species. Fungicolous species obtain nutrients by growing on other fungi and can be parasites, commensals or saprobes. In this study we used light and electron microscopy to study a species of Cladosporium found growing on the basidia of Exobasidium camelliae var. gracilis in an attempt to elucidate the nutritional relationship between the two species. E. camelliae var. gracilis is a plant pathogenic fungus that producing its basidia (Fig. 1) in a layer on the abaxial surface of an infected leaf of its host, Camellia sasanqua. A razor blade was used to obtain small pieces of infected leaves whose under surfaces were covered with basidia bearing discrete colonies of Cladosporium sp. (Fig. 2). Samples were prepared for study as follows. For SEM a standard fixation procedure [1] involving the use of glutaraldehyde and $\mathrm{OsO}_{4}$ was employed. Following fixation, samples were washed in distilled water, dehydrated in a graded ethanol series and critical point dried. Samples were mounted on specimen stubs using conductive tape, sputter-coated with gold and examined using a JEOL 6400 microscope operating at $15 \mathrm{kV}$. For TEM, samples were fixed as described above, dehydrated and infiltrated in Spurr's resin [2]. Following resin polymerization, thin sections of samples were cut using an ultramicrotome equipped with a diamond knife, collected on slot grids, allowed to dry on formvar-coated aluminum racks, post-stained and examined with a Zeiss $902 \mathrm{~A}$ microscope operating at $80 \mathrm{kV}$. For light microscopy, approximately $1 \mu \mathrm{m}$ thick sections of fixed samples were cut with a diamond histo-knife, collected on glass microscope slides, stained with toluidine blue $\mathrm{O}$ and examined and photographed using bright field light microscopy.

Young healthy basidia of E. camelliae var. gracilis appear as erect, swollen hyphal tips lining the undersurface of an infected leaf (Fig. 1). Fig. 3 shows the hyphae and spores in a colony of Cladosporium $s p$. growing on a layer of basidia. A light microscopic view of a section of a similar colony is shown in Fig. 4. As evident in Fig. 4, the underlying basidia are completely collapsed. However, a few intact basidia are evident near the margin of the colony. Examination of thin sections with TEM provided no evidence that hyphae of Cladosporium sp. actually penetrate living basidia. It appears that Cladosporium sp. somehow causes the underlying basidia to undergo lysis and release their contents. The hyphae of Cladosporium sp. then appear to grow in a saprobic fashion as they ramify throughout this dead material. This is in contrast to the situation in some species of Cladosporium in which their hyphae actually penetrate living hyphae and spores of their host fungi.

[1] K. Enkerli et al., Can. J. Bot. 75 (1997) 1493

[2] J. Taylor and C. W. Mims, Can. J. Bot. 69 (1991) 1207 


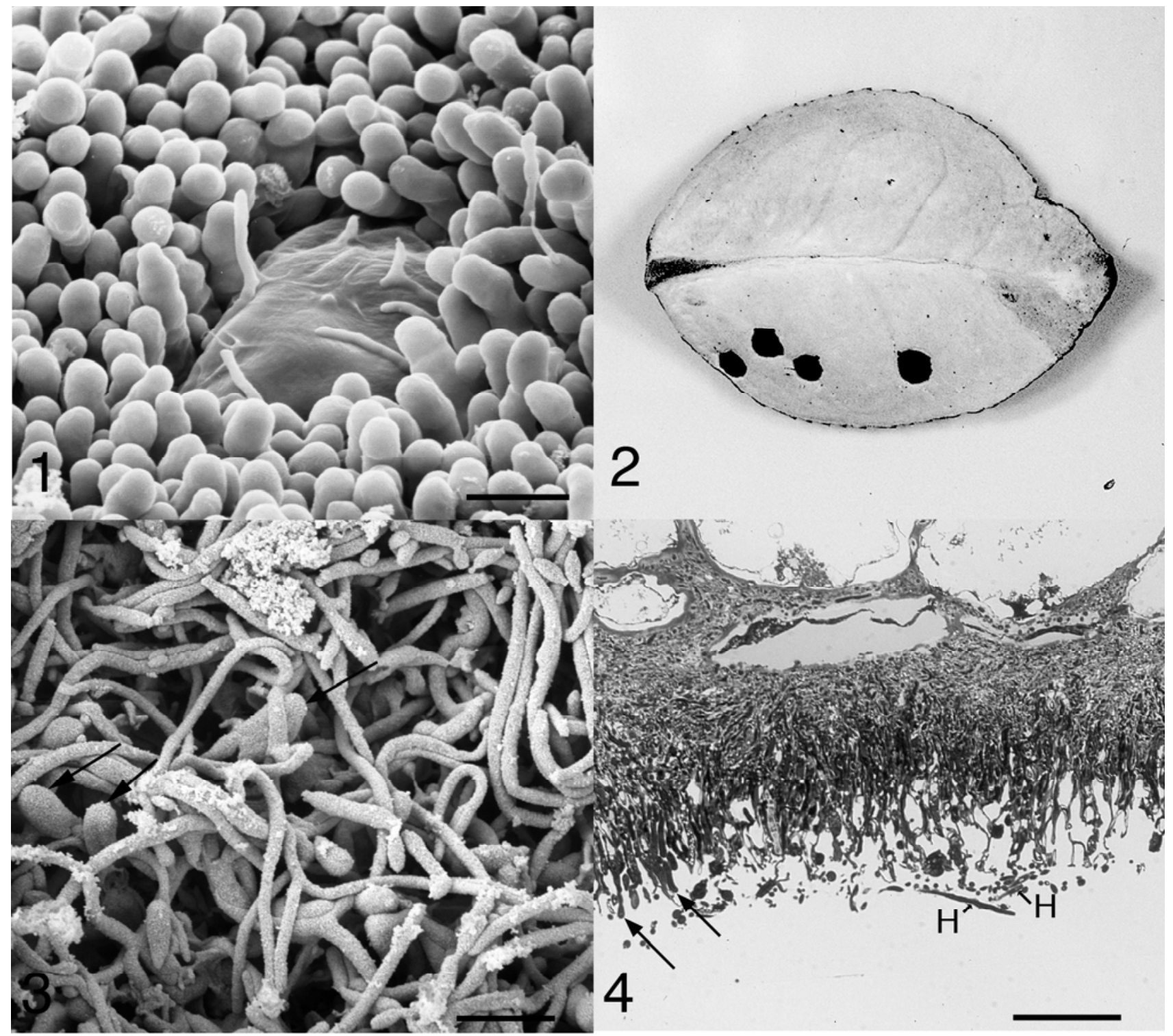

FIG. 1. Scanning electron micrograph of basidia of Exobasidium camelliae var. gracilis on the underside of an infected leaf of Camellia sasanqua. Bar $=20 \mu \mathrm{m}$.

FIG. 2. A near life size image showing a white felt-like layer of basidia on the underside of an infected leaf. The four dark regions that are visible are colonies of Cladosporium sp.

FIG. 3. Scanning electron micrograph of hyphae and spores (arrows) of Cladosporium sp. growing over the basidia of Exobasidium camelliae var. gracilis. Bar $=20 \mu \mathrm{m}$.

FIG. 4. Light micrograph of a thick section of a colony of Cladosporoium sp. stained with toluidine blue $\mathrm{O}$. A few hyphae $(\mathrm{H})$ of Cladosporium are visible. Note the absence of intact basidia above the hyphae. A few intact basidia (arrows) are visible near the margin of the colony. Bar $=0.05 \mathrm{~mm}$. 